\title{
An integrated model of metaphorical linguistic expressions and its implications for the semantics of verb-particle constructions
}

\author{
Ariadna Strugielska \\ ariadnas@umk.pl \\ Nicolaus Copernicus University, Poland
}

\begin{abstract}
The aim of this article is threefold. Firstly, in line with the current tendencies in cognitive linguistics, which direct research toward convergence, integration and a uniform theoretical perspective, recent developments in research pertaining to metaphorical linguistic expressions (MLEs) are discussed against explorations into the semantics of verb-particle constructions (VPCs) in order to demonstrate that these methodologies converge on both the type of questions asked and the kind of solutions proposed. Thus, the second aim of the present exposition is to propose an exemplar-based model of analysis which could be applied to the meaning profiles of both MLEs and VPCs. Finally, in view of the fact that previous approaches to metaphorical language have rather consistently downplayed the role of grammatical categories in meaning disambiguation, the article seeks to establish the function of VPCs in the meaning profiles of MLEs.
\end{abstract}

Keywords: MLEs, VPCs, cognitive linguistics, usage-based approach, isolating and integrating models, meaning profiles

\section{INTRODUCTION}

In their assessment of the cognitive linguistics enterprise, Evans and Green (2006: 779) note that one of the challenges the paradigm has yet to face is the problem of competing explanations offered to account for the same, or closely related, phenomena. As the authors further argue, conceptual projection constitutes a par excellence instantiation of competition among theoretical perspectives embedded in the cognitive commitment. Indeed it seems that Conceptual Metaphor Theory (henceforth also CMT), proposed by Lakoff and Johnson (1980) and developed by Kövecses (2000, 2002), Deignan (2005) and Stefanowitsch (2006), among others, has engendered some of the most heated debates within the community. As a result of the criticism the approach has received, CMT, at least in its classic version, is now placed outside cognitive linguistics (see, for instance, Givón 2005, Haser 2005). To be more specific, the tendencies within the standard metaphor model which go against mainstream research in cognitive linguistics 
An integrated model of metaphorical linguistic expressions and its implications for the semantics of verbparticle constructions

can be formulated as its overgeneralization and de-contextualization commitments. Consequently, it can be further argued that Conceptual Metaphor Theory is an isolating methodology, whereby the number of contexts competing for salience in the process of meaning interpretation is limited (cf. Geeraerts 2003).

\section{CMT AS AN ISOLATING MODEL}

The specific concerns related to the cognitive validity of Lakoff and Johnson's proposal concentrate on two aspects of CMT, which, as argued above, constitute the isolating commitment of the methodology.

Firstly, the degree of detachment between conceptual schemas and their linguistic realizations is taken as evidence against the plausibility of the generalizations proposed. This entails that a predetermined route of conceptual integration posited in CMT, i.e., a cognitive path that leads via the main meaning focus of the source category, is considered unmotivated.

The second major criticism which Conceptual Metaphor Theory has stimulated pertains to the role of context in meaning interpretation. To be more specific, if we assume that cognitive linguistics is a usage-based model, it must be concluded that the linguistic evidence quoted in support of CMT does not, on the whole, conform to this requirement. Indeed, a systematic overview of metaphorical language shows that there is still an urgent need within metaphor research to develop a methodology which would be more compatible with the usage-based postulate of cognitive linguistics.

\section{II.1. Metaphorical linguistic expressions}

The construct of a metaphorical linguistic expression was coined by Kövecses (2002: 251), who defines it as “... words or other linguistic expressions (e.g. idioms) that come from the terminology of the conceptual domain that is used to understand another conceptual domain”.

This definition of metaphorical language, derived from Lakoff and Johnson's (1980) proposal, entails numerous methodological ambiguities that are discussed, for instance, 
in Stefanowitsch (2006). For the sake of the current exposition, two interconnected limitations inherent in metaphorical expressions will be analyzed: their linguistic scope, i.e., the amount of syntagmatic context considered as relevant in the process of meaning interpretation, and their conceptual scope, i.e., the number of domains a particular linguistic unit is considered to evoke, both of which are discernible in examples (1)-(7) below (cf. Kövecses 2002).

(1) He's without direction in life.

(2) I'm where I want to be in life.

(3) She'll go places in life.

(4) He's never let anyone get in his way.

(5) She's gone through a lot in life.

(6) I'm starved for affection.

(7) He thrives on love.

Clearly, on the basis of the above data, metaphorical linguistic expressions, i.e., the underlined fragments in examples (1)-(7), are either content words, e.g. thrives, or collocations, e.g. go places, often arbitrarily limited, e.g. go through rather than go through a lot. What is of particular interest here is the role of VPCs, particles, and prepositions in the scope of MLEs. On the one hand, in examples (1)-(7), prepositions are not consistently included within metaphorical language. On the other hand, though, the mappings proposed are supported primarily by particles. For instance, the HAPPY IS UP metaphor is instantiated by four linguistic expressions, three of which, i.e., the underlined fragments in examples (8)-(10), are isolated particles:

(8) We had to cheer him up.

(9) Lighten upp!

(10) She lit up.

(11) They were in high spirits. (Kövecses 2002: 85)

All in all, then, it seems that MLEs are limited rather arbitrarily, which, in some cases, results in positing expressions whose frames do not include the metaphorical focus. For example, Kövecses (2000: 75), discussing She was consumed by passion or I am burning with emotion, as instances of the EMOTION IS FIRE/HEAT mapping, claims that "[i]t is the prepositions with and by that indicate that there is a causal link between 
An integrated model of metaphorical linguistic expressions and its implications for the semantics of verbparticle constructions

certain emotional responses and emotion as fire”. However, the prepositions, as the underlined fragments indicate, are excluded from the scope.

In the same vein, Steen's procedure of metaphor identification does not incorporate prepositions and particles into the analysis because “... they are somewhat less easy to handle [since] [m]any prepositions are delexicalized, which presents special problems for analysis and hence identification” (Steen 2002: 25). Related to this, Stefanowitsch’s (2006: 73) proposal to capture metaphorical language in the form of patterns which “... are presented in a form that is somewhat abstracted from the actual citations: verbs are shown in the infinitive, slots for participants are shown as $\mathrm{X}$ or $\mathrm{Y}$, and similar patterns are collapsed into compact form using slashes for alternatives and parentheses for optional elements” eliminates grammatical elements from the syntagmatic context. Not unexpectedly, prepositions and particles are among the most frequently omitted categories, as illustrated by the following examples: anger boil (up)/simmer (inside $X /$ beneath surface), $X$ vent anger (against $Y$ ), anger spark/flare (in $X$ 's eyes), $X$ arouse anger (in Y) (Stefanowitsch 2006: 74, 76).

To sum up, the examples of MLEs discussed above confirm the isolating character of CMT through the imposition of unmotivated constraints on the number of possible contexts influencing the construal of the target concept. As a result, not only are abstract categories, e.g. emotions, defined in a monolithic way but also sense relations among concepts are presented in a manner which induces identity. Importantly, categories whose status within MLEs is particularly problematic are function words and constructions, including VPCs. Consequently, the role of grammatical categories in meaning interpretation should be one of the central questions addressed in a usagebased, or integrated, approach to metaphorical language.

\section{TOWARD AN INTEGRATED MODEL OF METAPHORICAL LINGUISTIC EXPRESSIONS}

In the previous section, I have demonstrated that classifying CMT within a usage-based cognitive linguistics is debatable on account of the fact that the methodology is consistently detached from the influences of the linguistic context, which naturally 
entails that its conceptual commitment is rather limited. In an attempt to re-attach CMT to mainstream research within the cognitive paradigm, two avenues of exploration have been followed. The first one is a theory-driven attempt to reformulate conceptual metaphors as detailed mappings, while the other one aims at re-contextualizing MLEs. The two tendencies can thus be discussed as integration through specification and integration through re-contextualization, respectively.

\section{III.1. Integration as specification}

The first line of research guided by the principles of a usage-based perspective has sought to remedy the problems of unmotivated generalizations by positing detailed conceptual mappings. The resulting proliferation of source and target domains, however, has immediately prompted the question of a motivated connection between a linguistic unit and its domain matrix. In other words, as Haser (2005: 245) rightly observes, if “... every metaphorical expression could be 'accounted for' by different conceptual metaphors, ... not a single metaphorical concept is supported by the available data”. A similar idea is noted by Givón (2005: 80), who argues that conceptual primitives are activated by the categories within the utterance itself rather than metaphorical schemas.

Apparently, then, attempts at overcoming the problem of metaphorical generalizations have provided evidence for the direct access view upon linguistic metaphors (cf. Gibbs 2002).

Consequently, the meaning potentials of words and constructions constituting an MLE have been considered with reference to their most salient parameters, which could act as profile determinants. In search for the relevant aspects of meaning potentials, Hanks (2006) argues that the most prominent features are those which are important from the human perspective, and thus, “... mountains are high, deserts are dry, jungles are impenetrable, seas and oceans are vast expanses, heaven is nice, hell is nasty; storms are violent, attacks are damaging, drowning is slow death, burning is quick destruction, orgies are unrestrained” (Hanks 2006: 20). Moreover, Hanks argues that these attributes are preserved in cross-domain mappings. 
An integrated model of metaphorical linguistic expressions and its implications for the semantics of verbparticle constructions

At this stage, one cannot fail to notice an interesting parallelism between research into VPCs and investigations into the semantics of MLEs, which is constituted by the notion of the functional attributes of complex primitives. Indeed Hanks' observations are consistent with Navarro’s (2006: 171) proposal, whereby “... the functional patterns conceptualized on the basis of human interaction are also used for the conceptualization of spatial relationships between other entities". In other words, both lines of research seem to converge on the cognitive supremacy of human-calibrated representations.

All things considered, it seems that a direct access approach to metaphorical language has led to the extension of the conceptual commitment adopted by the methodology. Still, increasing the conceptual scope of one category, i.e., the source domain, does not seem to have solved the problem of a (postulated) usage-based orientation of the model. Obviously, the remaining conundrums pertain to the potential influences of other categories to be found within the scope of a metaphorical linguistic expression, and are thus closely related to the other avenue of research aimed at re-establishing the position of CMT within cognitive linguistics, i.e., studies highlighting the role of context in meaning interpretation.

\section{III.2. Integration as re-contextualization}

As announced above, attempts to re-formulate metaphorical mappings have been accompanied by research into the quantity and quality of the syntagmatic scope of MLEs. Importantly, a systematic study of natural contexts has revealed a number of mechanisms that are inaccessible through other perspectives, e.g. introspection. First of all, Deignan's (2005) analysis of linguistic metaphors provides evidence for the conceptual salience of the target category, which is consistently reflected in the morphosyntactic patterns typical of the non-literal uses alone. Likewise, Glynn’s (2002) study shows that numerous details pertaining to the conceptual structure of an abstract category can be revealed if a lexical approach is complemented by grammatical evidence. Related to this, Stefanowitsch's (2006: 66) construct of a metaphorical pattern, defined as “... a multi-word expression from a given source domain... into which a specific lexical item from a given target domain... has been inserted” highlights 
the importance of a coherent scope. Finally, Janda and Solovyev's (2009: 376) notion of a constructional profile of a lexeme which refers to “... the distribution of relative frequencies of constructions associated with a given word" places research into the structure of abstract concepts firmly within a family of usage-based methodologies including, for instance, Evans' (2006) lexical profiles or the co-occurrence patterns discussed by Svanlund (2007).

Basically, then, recent approaches toward metaphorical language highlight the role of the linguistic (and conceptual) scope in a comprehensive description of a particular unit since "[a] word's constructional profile is [taken as] unique and representative of its meaning” (Janda and Solovyev 2009: 376). Simultaneously, it is important to note that the developments in the study of MLEs presented above are again consonant with recent proposals within research on VPCs. For instance, Silvestre (2008: 396-397) observes that:

[t]he specific senses that linguistic units in general, and relational particles in particular, take in discourse are influenced by the linguistic and extralinguistic context in which they are employed. Hence, the uncovering of the nature of contextual elements, like sets of Trs and Lms typically occurring with specific VPCs, helps to better understand the semantics of these constructions.

The profiles, or scopes, of MLEs or VPCs are thus aggregates of categories whose meaning potentials cannot be ignored in the process of conceptual integration. In the same vein, Dobrovol’skij and Piirainen (2005: 155) claim that “... idioms related to the FEAR IS COLD metaphor render ambivalent interpretations. Thus, it is vital to consider not just the actual figurative meanings but also the conceptual structures behind them." Consequently, Dobrovol'skij and Piirainen define FEAR through a number of (functional) aspects revealed through the study of syntagmatic settings, e.g. "for a long time", "suddenly", "immediately", or the "degree of acceptability of the subject's emotional state from the perspective of the speaker”. To illustrate, examples (12)-(13) are considered to highlight "personal" as opposed to "non-personal" aspects of the emotion (cf. Dobrovol'skij and Piirainen 2005: 155).

(12) I had my heart in the mouth when I went to ask the bank for more money.

(13) All those watching the attempt to save the drowning child had their hearts in their mouths. 
An integrated model of metaphorical linguistic expressions and its implications for the semantics of verbparticle constructions

Evidently, Dobrovol'skij and Piirainen's proposal offers a much-needed extension of the metalanguage (of standard CMT) and makes it possible to highlight connections within and across target domains which cannot be explained in terms of relations in (apparently co-activated) source categories. Interestingly, this line of research has also been pursued with reference to VPCs.

In her study of the contextual realizations of the UP schema, Hampe (2005: 104) claims that it is instructive to consider the conceptual structures behind the actual linguistic expressions rather than “... introducing an axiological orientation of its own [since] the particle is indeed capable of emphasizing or enhancing the evaluative aspects already inherent in the respective scenarios expressed by the verbs and their complements". Moreover, Hampe draws attention to one problem within VPC studies which is also relevant in the case of MLEs, i.e., the issue of competition among categories within a specific syntagmatic context. To be more specific, in view of the fact that VPCs, and also MLEs, have been associated with particular aspects in isolating methodologies, it is important to check the validity and/or stability of these features from a usage-based perspective.

I believe that the above-mentioned concerns pertaining to the cognitive salience of aspects predicated of isolated categories need to be interpreted against a general discussion in cognitive linguistics on the plausibility of the notion of profile determinance. While details of the dispute can be found in Croft (2001), Langacker (2008), and Taylor (2002), what is of utmost importance for the current exposition is the relation between a unit's prominence and its likelihood of functioning as the head within a complex assembly.

To begin with, Ungerer and Schmid (1996) argue that the head/modifier asymmetry is related to the cognitive salience of categories. Salience, in turn, means that a given construct is “... particularly vital for human concerns” (1996: 92). For instance, in the case of shoelace, the category SHOE is seen as more important for human purposes than that of LACE, and consequently the former is the head. Not unrelated to this, Croft (2001: 259) claims that the head is “... the primary information-bearing unit, that is, the most contentful item”. On the other hand, according to Taylor (2002: 349-350), in a nominal “... the profile of the composite expression is inherited from the determiner, 
not from the bare noun. ... The bare noun is therefore the complement of the determiner”. Langacker's (2008: 192, 194) approach to profile determinance in fact sanctions both the structural and the semantic definition of the construct, while Tuggy (2007: 115) points to a possible irresolvability of the grammatical/lexical primacy.

Clearly, then, a unit's salience depends on its class membership and it seems that grammatical words and at least some content items are potential candidates for prominence within a syntagmatic context of a metaphorical linguistic expression.

To continue, Goldberg and Casenhisher (2006) argue that, depending on their respective degrees of entrenchment, it is either the construction or the main verb that determines the interpretation of the sentence. For instance, in Mike gave her a pencil, the understanding is assumed to come from the verb give rather than the ditransitive construction. Another tendency is noted by Fillmore (2003), who refers to give in give her a kiss as a "ditransitive support verb”. The particular context in which give occurs renders it non-salient and hence, according to Fillmore, the semantic determinant is the direct object.

What transpires from the above overview is an inference that since a unit's salience is relative, profile determinance seems best defined as a dialogical notion. Consequently, it may well be the case that a number of salient categories are characteristic of a particular context, none of which can be felicitously proposed as a profile determinant. This idea is reinforced by the fact that isolated meaning potentials undergo transformations in the process of conceptual integration to such a degree that their purports become mere ingredients of the whole (cf. Croft and Cruse 2004: 101). Therefore, I postulate the context of (at least) an utterance to function as a complex primitive, i.e., a locus of functional attributes. This suggestion is based on Croft's model of exemplar-based grammar, which takes:

[e]ach situation/scene as a whole [as] a primitive element in the representation, i.e., a point in conceptual space. To put it another way, each semantic frame is a semantic primitive. Likewise, each construct is a primitive element in the representation, a point in syntactic space. (Croft 2007: 27)

As a result of adopting an exemplar-based approach to MLEs, units within a context can be evaluated with reference to their relative salience and, consequently, meaning profiles of MLEs can be developed, which, in essence, consist of recurrent aspects 
An integrated model of metaphorical linguistic expressions and its implications for the semantics of verbparticle constructions

attracted by a particular collostruction. Further details of the proposal are presented below and these, in view of the systematic convergences highlighted throughout this article, could be pertinent to research concerning the semantics of VPCs.

\section{METAPHORICAL LINGUISTIC EXPRESSIONS IN THE INTEGRATED MODEL}

As already argued above, the integrated methodology assumes the context of an utterance as the starting point and, hence, the global complex primitive is an exemplar. Within each exemplar, local loci of functional attributes can be distinguished, which are predominantly conveyed via grammatical words and constructions. A metaphorical linguistic expression is thus only one of the many complex primitives which can be found in an utterance. Consequently, its salience is relative and depends on the prominence of the other elements within an exemplar. Therefore, the aspects proposed as highlighted by a given MLE in the isolating approach are likely to be, at least qualitatively, different in the integrated model. Moreover, building on the assumption that conceptual integration involves establishing correspondences, even the most schematic ones, among the participating elements, it is assumed that the components underscored in the meaning profiles of MLEs are at least as relevant to their semantics as those posited in the isolating approach. The specific assumptions of the model are formulated below.

To begin with, as argued in Section II.1, the very definition of a metaphorical linguistic expression requires elaboration and, thus, I assume that an MLE is a collostruction composed of two units, one of which designates a concrete concept and the other an abstract one. Moreover, since the function of MLEs is to reveal the underlying semantic potential of abstract concepts e.g. emotions, which, in turn, are conveyed via nouns, I take MLEs realized by noun phrases, e.g. cold fear, bitter anger or source of sadness as prototypical members of the category. Next, MLEs are presumed to be ambiguous since, first of all, the very notion of metaphoricity implies multiple, and often competing, interpretations (cf. Haser 2005: 170). This assumption is reinforced by the fact that MLEs are isolated phrases whose meanings, as Boas (2003) rightly notes, are

Language Value 3 (1), 30-48 http://www.e-revistes.uji.es/languagevalue 
unlikely to be determined due to a lack of contextual clues. In the same vein, Stern (2000: 179) claims that “... metaphors are never expression types per se but interpretations (or uses) of expression tokens in contexts”. Consequently, I propose that both the salient aspects of meaning potentials and the degree of cognitive distance between the elements of an MLE can be reliably established on the basis of an integrated, i.e., exemplar-based, approach.

In order to illustrate the workings of the methodology, let us first of all look at Hanks' (2006) examples of MLEs, whose metaphoricity is motivated by the degree of resonance between the primary and secondary subjects, which Hanks defines as the number of semantic features shared by the two categories. Consequently, sea of faces is an unprototypical MLE, while sea of trouble is far more representative of the category. Moreover, Hanks posits that in the case of the sea of $N$ construction, the salient functional attribute is vastness, which is consistently inherited by the complex assembly. If this speculation is confirmed by means of an integrated methodology, it will be concluded that a usage-based approach is redundant since it, on the whole, confirms the aspects already revealed in an isolating model. If, on the other hand, syntagmatic contexts were to show functional attributes other than those posited in CMT, the validity of the methodology would be increased.

As a result of verifying Hanks' examples, the aspect of vastness has been partly confirmed in the syntagmatic settings of sea of faces, since of the 19 corpus citations checked, seven co-occur with contexts related to unboundedness, which is illustrated by examples (14)-(20).

(14) She looked down upon a sea of faces, rows and rows of black-stockinged legs, and a long line of mistresses sitting on their chairs.

(15) For a second she blacked out, not from pain but from the shock of it all, and when she opened her eyes she was looking into a sea of faces all staring down at her.

(16) She'd deliberately looked into the sea of faces, looked unerringly to the rear of the crowded room.

(17) She glanced up with dread and peered into the sea of faces that was watching her with curiosity.

(18) She ignored his lecherous gaze and scanned the sea of faces for Stephen. 
An integrated model of metaphorical linguistic expressions and its implications for the semantics of verbparticle constructions

(19) Now she reached the main doors and walked in, eyes flicking over the sea of faces in search of Mahoney.

(20) Obediently the noise level dropped to a whispered exchange, and Larsen ran his eye over the sea of faces packing the long corridor on either side, trying to pick out his daughter Karen.

In the case of sea of troubles, however, the corpus examples point to a connection between the phrase and the CONTROL schema, as illustrated by examples (21)-(22).

(21) Whether 'tis nobler in the mind to suffer The slings and arrows of outrageous fortune, Or to take arms against a sea of troubles, And by opposing end them?

(22) Had it not been for that publication Sally might have avoided that almost overwhelming sea of troubles which resulted from harmlessly intended praise.

Finally, the contexts of sea of life present the following picture:

(23) Much better to get involved with someone who had plunged fully into the sea of life than with someone who had stood wimpishly on the edge, afraid to dip in so much as a toe.

(24) It is someone who is not afraid of responsibility or commitment, whose daily disciplines provide an anchor in the rough sea of life, who does not switch his allegiance, whatever the cost.

(25) Now you've been patched up, your hull's been scraped, a lick of paint and you're ready to get back into the great sea of life.

Thus, sea of life may well be associated with such concepts as EXCITEMENT, DANGER or even WAR. However, the link is not as obvious as in the case of, for instance, sea of faces. For one thing, more context, probably as extensive as the underlined fragments in examples (23)-(25), is needed in order to discover the salient aspects.

Two important implications emerge from our discussion so far. Firstly, MLEs are ambiguous collostructions whose meaning potentials only partly confirm the aspects proposed in isolating approaches. This is not to say that vastness/unboundedness is not a possible element of the meaning potential of, for instance, sea of trouble. However, it is to say that this aspect is not revealed in the meaning profile of the cluster. Consequently, sea is seen as a complex primitive which competes for salience with 
other loci of functional attributes within an exemplar, e.g. VPCs. Simultaneously, let us recall that the complex primitives within a context can be realized by linguistic means of varying prominence. For instance, Goldberg (2006: 104-119) argues that although the cue validity of words and constructions is roughly the same, it is nevertheless the latter that have a more significant predictive potential. Related to this, grammaticalization theories postulate the role of high-frequency lexical words and expressions, e.g. body part terms, verbs expressing physical states or processes, e.g. sit, lie or go, or verbs expressing core human activities such as make, do, have or say in meaning interpretation (cf. Heine et al. 1991: 32-35).

In view of the above, I propose a grammar-based metalanguage for the description of the meaning profiles of MLEs, whose validity is further supported by research into simulation semantics. To be more specific, abstract categories, which constitute the core of MLEs, are highly attenuated simulations of engaged experience. Thus, in consonance with the mechanics of conceptual integration, the meaning profiles of MLEs are expected to display features which are consistent with those anticipated by the cluster. Consequently, the metalanguage applied for the representation of abstract concepts is supposed to include categories which transcend immediate experience, i.e., grammatical meanings (cf. Langacker 2008: 540). All in all, basic concepts derived from grammatical categories, e.g. conjunctions, prepositions, determiners, VPCs or syntactic patterns, are taken as par excellence complex primitives.

An inventory of basic concepts for the representation of the meaning profiles of MLEs includes both object-based schemas, e.g. EXPERIENCER, CO-OBJECT or EXPRESSION, and relations, e.g. AVAILABILITY TO OTHERS, CONTROL, PENETRATION, PERSISTENCE or CONTRIBUTION (for a comprehensive set, see Strugielska forthcoming). These complex primitives occur within the contexts of metaphorical linguistic expressions, as illustrated by examples (26)-(29), where MLEs are represented by $\mathrm{X}$ and the underlined fragments are the approximate linguistic realizations of the basic concepts proposed.

(26) (Nuadu did not move,) but the icy fear closed about him again. (PERSISTENCE, X, EXPERIENCE/CONTROL, PERSISTENCE) 
An integrated model of metaphorical linguistic expressions and its implications for the semantics of verbparticle constructions

(27) The icy fear which showed in the older man's eyes cut through Vologsky’s mild concern like a knife, chilling him to the bone. (X, AVAILABILITY TO OTHERS, EXPERIENCER/EXPRESSION, PENETRATION, PENETRATION)

(28) (As he dressed for dinner in his room, Dorian remembered what he had seen) and cold fear ran through him like a knife. (RESULT, X, PENETRATION, PENETRATION)

(29) She struggled with the cold fear that had laid its hand on her. (RESISTANCE, X, CONTROL)

According to CMT, the aspect highlighted by cold/icy fear is a negative valuation. However, the integrated approach shows that there are a number of other attributes relevant to the meaning of the cluster. Importantly, these aspects, e.g. PENETRATION, RESULT, or CONTROL, are, in my view, prototypically functional since they facilitate the construal of the emotion from the human perspective, i.e., as regards its intensity.

Finally, let us consider deep sadness and deep fear in order to highlight further advantages of the integrated model.

The cluster deep sadness consistently features three aspects within its meaning profiles: EXPRESSION, EXPERIENCER and AVAILABILITY TO OTHERS, as demonstrated by examples (30)-(35).

(30) It was, however, obvious that there was some deep sadness within him.

(31) Little by little his shoulders bent forward, and his face showed deep sadness.

(32) On his face was a look of deep sadness, but also of evil.

(33) On his face was an expression of deep sadness.

(34) (Montgomery had expected an air of authority from this venerable man, who had spent most of his seventy-odd years lecturing students,) but Aubrey St John Goth seemed distant, distracted, his grey eyes veiled by a deep sadness.

(35) He felt a deep sadness in this thin, weak creature.

On the other hand, the meaning profiles of deep fear are not only quantitatively but also qualitatively different (see examples 36-42).

(36) The need for excessive control in conversation can come from a deep fear that other people's ideas are threatening. (CAUSE, X, CO-OBJECT/CAUSE) 
(37) One more guilty secret that Maggie felt obliged to keep from everyone was the deep fear and disgust that she felt at the thought of sexuality. (SOCIAL ACCEPTABILITY, NON-AVAILABILITY TO OTHERS, X, CAUSE)

(38) In England the desire for an "English" tradition is said to hide a deep fear of our present multi-cultural society, a determination to maintain our present class structure, the hierarchies of power which give Oxbridge dons their privileged and cushioned existence. (SOCIAL ACCEPTABILITY, NON-AVAILABILITY TO OTHERS, $\mathrm{X}$, EXPERIENCER)

(39) The colour left her skin, her pale face showing a deep fear at the way he was crushing her to his body. (EXPRESSION, AVAILABILITY TO OTHERS, X, CAUSE)

(40) In no way had he been consciously sadistic over the earlier years, but he had a deep fear of women who took over, as his mother had done. (AVAILABILITY TO SELF, EXPERIENCE, X, CO-OBJECT/CAUSE)

(41) The warm, soft-seeming lead beneath her feet and the sharp-knapped flint and stone under her hand only partially secured her against the deep fear of falling. (PROTECTION, X, CO-OBJECT/CAUSE)

(42) A general war weariness, grievances over high taxation, and a deep fear amongst the Anglican majority of the population that the Church was now in greater danger from Protestant Nonconformists than it was from popery, all worked to the Tories' advantage. (X, EXPERIENCER, CO-OBJECT/CAUSE, CONTRIBUTION)

The meaning profiles of MLEs presented above point to two important implications of the model proposed here. To begin with, an exemplar-based analysis highlights aspects of meaning potentials of collostructions which are unavailable through an isolated perspective. However, these features are important for the semantics of MLEs on a few counts. Firstly, a systematic analysis of meaning profiles facilitates ambiguity/conventionality distinctions, which can be accomplished on the basis of the number and productivity of aspects. Consequently, deep sadness seems a less ambiguous, i.e., metaphorical, cluster than deep fear. Related to this, sense relations among MLEs can be established on the basis of meaning profiles, which will inevitably result in delimiting the rampant synonymy position of CMT. Next, depending on the degree of attenuation of aspects within exemplars, MLEs could be placed along the concrete/abstract continuum in a motivated way, whereby highly schematic concepts, 
An integrated model of metaphorical linguistic expressions and its implications for the semantics of verbparticle constructions

e.g. CO-OBJECT, would indicate a greater degree of abstraction than categories such as RESISTANCE or PENETRATION.

The second implication of the model pertains to the role of grammatical categories, e.g. VPCs, in the profiles of MLEs. As amply illustrated above, the uncertain status of function words posited in CMT is not confirmed in the integrated model, where the functional attributes are predominantly derived from grammar. To be more precise, I posit that aspects inherent in the cognitive models behind particular MLEs are conveyed via grammatical categories, while less intrinsic ones, e.g. SOCIAL ACCEPTABILITY or VALUATION, are realized by content words. Consequently, VPCs, which refer to the central attributes of the MLEs discussed above, e.g. CONTROL, PENETRATION, AVAILABILITY TO OTHERS or CAUSE, can, on the whole, be seen as indispensable in the meaning profiles of metaphorical linguistic expressions.

\section{CONCLUSIONS}

Three main conclusions arise from the current exposition. Firstly, and perhaps most importantly, there are theoretical implications, which clearly show points of convergence between the VPC and MLE methodologies as well as their unquestionable position within a usage-based cognitive linguistics. Consequently, the article addresses one of the remaining challenges of the paradigm, which is to forge a uniform theoretical position that could be shared by the multifarious proposals classifying themselves as “cognitive”. Secondly, and related to this, an integrated model of MLEs has been proposed, and its relevance for VPCs has been highlighted. Finally, it has been evidenced that the meaning profiles of MLEs are predominantly composed of grammarbased conceptual primitives and, thus, the role of VPCs for the interpretation of metaphorical linguistic expressions has been emphasized.

In view of the above, it can be firmly stated that explorations into the semantics of MLEs and VPCs have much to offer not only to each other but also to other usagebased methodologies within cognitive linguistics. 


\section{REFERENCES}

Boas, H.C. 2003. A Constructional Approach to Resultatives. Stanford: Center for the Study of Language and Information.

BNC: The British National Corpus XML World Edition. 2007. Oxford: Oxford University Computing Services.

Croft, W. 2001. Radical Construction Grammar. Syntactic Theory in Typological Perspective. Oxford: Oxford University Press.

Croft, W. 2007. “Exemplar semantics”. 10 June $2011<$ http://www.unm.edu/ $\sim_{\text {wcroft} /}$ Papers/CSDL8-paper.pdf>

Croft, W. and Cruse, A.D. 2004. Cognitive Linguistics. Cambridge: Cambridge University Press.

Deignan, A. 2005. Metaphor and Corpus Linguistics. Amsterdam: John Benjamins.

Dobrovol'skij, D.O. and Piirainen, E. 2005. Figurative Language: Cross-Cultural and Cross-Linguistic Perspectives. Amsterdam: Elsevier.

Evans, V. 2006. “Lexical concepts, cognitive models and meaning-construction”. Cognitive Linguistics, 17, 491-534.

Evans, V. and Green, M. 2006. Cognitive Linguistics: An Introduction. Mahwah, NJ: Erlbaum.

Fillmore, C. 2003. “Multiword expressions: An extremist approach”. 22 March 2011 $<$ http://www.cis.upenn.edu/ ace/kick_off_nov2003/fillmore.ppt $>$

Geeraerts, D. 2003. "Decontextualizing and recontextualizing tendencies in 20th century linguistics and literary theory”. In Mengel, E., H.-J. Schmid and M. Steppard (Eds.) Anglistentag 2002 Bayreuth. Trier: Wissenschaftliger Verlag, 369-379.

Gibbs, R.W. 2002. "A new look at literal meaning in understanding what is said and implicated”. Journal of Pragmatics, 34 (4), 317-486.

Givón, T. 2005. Context as other Minds: The Pragmatics of Sociality, Cognition, and Communication. Amsterdam: John Benjamins. 
An integrated model of metaphorical linguistic expressions and its implications for the semantics of verbparticle constructions

Glynn, D. 2002. “Love and anger: The grammatical structure of conceptual metaphors”.

12 February 2011 <http://www.findarticles.com/p/articles/mi_m2342/is_3_36/ ai_94775630/?tag=content;col1>

Goldberg, A.E. 2006. Constructions at Work: The Nature of Generalization in Language. Oxford: Oxford University Press.

Goldberg, A.E. and Casenhiser, D. 2006. "English constructions”. In Bas, A. and A. MacMahon (Eds.) The Handbook of English linguistics. Oxford: Blackwell, 343356.

Hampe, B. 2005. “A usage-based assessment of the plus-minus parameter”. Cognitive Linguistics, 16 (1), 81-112.

Hanks, P. 2006. "Metaphoricity is gradable". In Stefanowitsch, A. and S.Th. Gries (Eds.) Corpus-Based Approaches to Metaphor and Metonymy. Berlin: Mouton de Gruyter, 17-35.

Haser, V. 2005. Metaphor, Metonymy, and Experientialist Philosophy. Berlin: Mounton de Gruyter.

Heine, B., Claudi, U. and Hünnemeyer, F. 1991.Grammaticalization: A Conceptual Framework. Chicago: University of Chicago Press.

Janda, L.A. and Solovyev, V.D. 2009. "What constructional profiles reveal about synonymy: A case study of Russian words for sadness and happiness”. Cognitive Linguistics, 20 (2), 367-393.

Kövecses, Z. 2000. Metaphor and Emotion: Language, Culture, and Body in Human Feeling. Cambridge: Cambridge University Press.

Kövecses, Z. 2002. Metaphor. A Practical Introduction. Oxford: Oxford University Press.

Lakoff, G. and Johnson, M. 1980. Metaphors We Live by. Chicago: University of Chicago Press.

Langacker, R.W. 2008. Cognitive Grammar: A Basic Introduction. Oxford: Oxford University Press. 
Navarro, I. 2006. “On the meaning of three English prepositions”. In Navarro, I. and N. Alberola (Eds.) In-Roads of Language: Essays in English Studies. Castellón: UJI Press, 167-179.

Silvestre, A.J. 2008. “The semantics of 'in' and 'on' in VPCs: A Cognitive Linguistics corpus-based analysis”. Ph. D. dissertation, Castellón: Universitat Jaume I.

Steen, G.J. 2002. “Towards a procedure for metaphor identification”. Language and Literature, 11 (1), 17-33.

Stefanowitsch, A. 2006. "Words and their metaphors: A corpus-based approach". In Stefanowitsch, A. and S.Th. Gries (Eds.) Corpus-Based Approaches to Metaphor and Metonymy. Berlin: Mouton de Gruyter, 61-105.

Stern, J. 2000. Metaphor in Context. Cambridge, MA: MIT Press.

Strugielska, A. forthcoming. Towards an Integrated Conceptual Model of Metaphorical Linguistic Expressions in English. Torun: Wydawnictwo UMK.

Svanlund, J. 2007. “Metaphor and convention”. Cognitive Linguistics, 18, 47-89.

Taylor, J.R. 2002. Cognitive Grammar. Oxford: Oxford University Press.

Tuggy, D. 2007. “Schematicity”. In Geeraerts, D. and H. Cuyckens (Eds.) The Oxford Handbook of Cognitive Linguistics. Oxford: Oxford University Press, 82-116.

Ungerer, F. and Schmid, H.-J. 1996. An Introduction to Cognitive Linguistics. London: Longman.

Received October 2011

Cite this article as:

Strugielska, A. 2011. "An integrated model of metaphorical linguistic expressions and its implications for the semantics of verb-particle constructions”. Language Value, 3 (1), 30-48. Jaume I University ePress: Castelló, Spain. http://www.e-revistes.uji.es/languagevalue.

ISSN 1989-7103

Articles are copyrighted by their respective authors 